\title{
Acoustic and seismic ambient noise measurements in urban and rural areas
}

For Submission to Applied Acoustics

Donald G. Albert and Stephen N. Decato (1) 


\begin{abstract}
Using portable sound level meters, simultaneous one-third octave spectral measurements of acoustic and seismic ambient noise as a function of frequency were conducted in different urban terrains and at two rural locations. The acoustic measurement frequency band of $6 \mathrm{~Hz}-20 \mathrm{kHz}$ includes frequencies lower than are commonly measured in acoustic surveys, while the seismic band of $6 \mathrm{~Hz}-1 \mathrm{kHz}$ extends to higher frequencies than most past seismic measurements. The urban acoustic measurements are dominated by traffic noise. The seismic signatures also are heavily influenced by traffic noise but exhibit more variation with respect to urban location due to the influence of subsurface conditions. For most urban measurement sites, the acoustic peak frequency was usually around $60 \mathrm{~Hz}$, while the peak seismic frequencies were usually less than $25 \mathrm{~Hz}$. The measured urban seismic spectra also tended to have more structure and variation in spectral shape from one location to another compared to the acoustic spectra, and a more rapid decline with increasing frequency, usually decreasing by about $30 \mathrm{~dB}$ from $30 \mathrm{~Hz}$ to $600 \mathrm{~Hz}$.
\end{abstract}

Keywords: Urban ambient noise, seismic noise, acoustic noise, geophone 


\section{Introduction}

Acoustic and seismic sensors have good potential for passive, non-line-of-sight, detection, localization, and monitoring of natural and human activities [Becker and Gudesen, 2000; Swanson, 2011]. However, to fulfill this potential, sensor algorithms must be designed not only to robustly identify signals of interest, but also to cope with environmental effects including high levels of background noise often found in urban areas. Although acoustic and seismic background noise has been extensively investigated e.g. [McNamara and Buland, 2004; Mennitt et al., 2014], knowledge gaps still exist for the frequency band of interest to ground sensors, roughly $10-1000 \mathrm{~Hz}$. This is higher than most seismic propagation studies, but lower than standard outdoor acoustic noise surveys. In addition, the variability of ambient noise in different urban locations is still a subject of investigation.

Although studies of acoustic ambient noise have been conducted for many decades, perhaps the majority of previous acoustic ambient noise measurements were conducted to determine or mitigate civilian noise exposure, especially in cities and towns. For example, Brown and Lam [Brown and Lam, 1987] references a study of urban noise published in 1930, while Steele [Steele, 2001] discusses a traffic noise model developed in the early 1950's. However because this type of study was focused on human effects, A-weighted filters were almost always applied to field recordings to mimic the loudness response of the human ear, severely attenuating the lower frequencies of interest to ground sensors. For example, A-weighting reduces the recording sensitivity by $-9 \mathrm{~dB}$ at $250 \mathrm{~Hz},-19 \mathrm{~dB}$ at $100 \mathrm{~Hz}$, and $-70 \mathrm{~dB}$ at $10 \mathrm{~Hz}$. In addition, the measurements often report some type of band-averaged noise or overall exposure levels without spectral information. While these studies have led to very detailed and useful models of traffic noise [Can et al., 2010; Wei et al., 2016], the measurement parameters limit their usefulness to other applications like sensor design.

In contrast, some acoustic surveys to determine the natural sound environment in quiet areas [Ambrose, 2006; Boersma, 1997; Lynch et al., 2011; Mennitt et al., 2014] do extend to lower frequencies and provide very useful spectral information in the form of third-octave spectra. The main limitation of this type of study is that they are usually conducted in quiet areas, and very few measurements are available in populated rural or urban areas where different noise characteristics are expected.

Seismic ambient noise studies also have a long history, dating back many decades [Banerji, 1924; Gutenberg, 1931]. A comparison of worldwide measurements [Brune and Oliver, 1959; McNamara and Buland, 2004; Peterson, 1993] shows a global high noise peak at a period of 6 seconds (approximately $0.1-0.2 \mathrm{~Hz}$ ) caused by water wave interactions with the ocean bottom. The lowest noise levels are in the $20-1000$ second period band $(1-50 \mathrm{mHz})$ so many seismic monitoring stations are designed to record these frequencies for teleseismic studies and nuclear test ban monitoring. Compilations from global seismic networks [McNamara and Buland, 2004; Peterson, 1993] typically cover the frequency range from below $1 \mathrm{mHz}$ to a few tens of $\mathrm{Hz}$, and seismic "high frequencies" are sometimes defined as those greater than $1 \mathrm{~Hz}$ [Withers et al., 1996]. A 100 sample per second recording rate is common, and early seismic measurements reaching $100 \mathrm{~Hz}$ are rare [Frantti, 1963]. However, because high frequency seismic measurements can provide useful discriminants between explosions and earthquakes, and with 
the increasing use of portable seismic networks installed near or at the Earth's surface, additional studies of noise up to $100 \mathrm{~Hz}$ have been conducted [Barstow et al., 1990; Berger et al., 1988; Carter et al., 1991; Given, 1990; Withers et al., 1996; Young et al., 1996], generally in quiet areas far from cultural noise sources. With the advent and improvements in digital technology, wider bandwidth studies are increasingly undertaken, and Peterson [Peterson, 1993] extended the standard noise model high frequency limit from 10 to $100 \mathrm{~Hz}$ based on the measurements of Li et al. [Li et al., 1984] for a very quiet desert area. At higher frequencies, wind and cultural noise become important and often dominate the frequency band above $10 \mathrm{~Hz}$.

More recently, improved recording equipment and data processing techniques have led to the use of passive seismic recordings of natural or human-generated noise, particularly traffic, to determine shallow Earth structure [Behm et al., 2014]. In urban areas, measurements show that human-generated noise becomes the dominate source above about $1 \mathrm{~Hz}$ [Groos and Ritter, 2009], and vehicles can be tracked using seismic arrays [Riahi and Gerstoft, 2015]. Specific efforts to acoustically track vehicles [Can et al., 2010; Moran et al., 2007] have also been reported.

Urban areas can be thought of as a human-built ecosystems, but until recently there have been few studies conducted in these areas compared to more pristine natural systems like open fields, forests, or wetlands. The US Department of Defense has developed a system of urban terrain zones based on studies [Ellefsen, 1987] of city morphology (the sizes and areal extent of streets and buildings) and general human activities (industrial, commercial, residential, etc). These terrain zones can be useful to describe particular locations and to select sites for studies of the urban environment, e.g. [Cionco and Ellefsen, 1998].

This paper discusses and documents experimental measurements conducted to characterize ambient noise properties in rural and urban environments over the frequency bands of interest to unattended ground sensors. The main goals of these measurements were to determine the amplitudes and frequency characteristics of both acoustic and seismic noise in urban areas, and to determine the variations in these noise spectra in different types of urban terrain. Standard measurement techniques were adapted and modified for the measurements in urban terrain and to permit vibration measurements to be made as detailed in the next section. The rural and urban measurement results are presented and discussed in the following sections.

\section{Measurement methods}

As discussed above, the goal of the measurements was to determine the characteristics of acoustic and seismic background noise in urban areas in frequency bands of interest for sensor applications and to investigate how the noise changes in different urban locations. The primary design requirements for these the measurements were that the equipment be small and easily portable, encompass the needed broad frequency band, and provide data in a compact form. While the rural measurements could run for long periods without interference, the urban measurements were limited to short time periods since permanent, secure sites were not available.

To meet these requirements, two Norsonic Model 118 integrating sound level meters (SLM) with one-third octave real time analyzers were used to record the acoustic and seismic ambient noise 
measurements simultaneously in the $6.3 \mathrm{~Hz}$ to $20 \mathrm{kHz}$ frequency range. These meters are handheld in size and easily portable, are powered by internal AA batteries, and have a wide dynamic range of $120 \mathrm{~dB}$. The integration and third-octave analysis functions also provide some data analysis and compression during the recording process. For example, instead of a lengthy time series (44 kHz x 24 hours results in $3.8 \times 10^{9}$ data values) or dense evenly-spaced frequency spectra, calculating and saving 36 third-octave frequency bin levels every minute (with suitable averaging) produces $5.2 \times 10^{4}$ three-digit numbers, a reduction factor of almost $10^{5}$ data values. The size of the recorded data remains much smaller than the full time series even when exceedance levels, standard deviations, and other statistical values are also saved. This equipment also eliminates possible privacy concerns by not recording unauthorized conversations of pedestrians on the street.

In contrast with spectral analysis methods using equally-spaced frequency intervals (per $\mathrm{Hz}$ being the most common), one-third octave bins increase with frequency as $2^{1 / 3} f_{c}$, where $f_{c}$ is the bin center frequency [Bormann, 1998]. This property will require corrections to the high frequency seismic measurements as discussed in Appendix A.

The SLMs have internal clocks that were synchronized by hand to within one second at the start of each measurement period. All of the measurements were conducted with the meters sampling the signals at a $48 \mathrm{kHz}$ sampling rate, using "fast" decay time constants of 125 milliseconds, and with flat $(Z)$ filtering instead of A-weighting. In addition, the SLMs calculated statistical quantities for each frequency bin at 0.1 second intervals. For the rural measurements, the microphone and the geophone were installed in a grass-covered, open field far from any reflecting objects like trees or buildings, and the record length was increased to 5 minutes so that a full day of recording produces 288 records. For the urban measurements, only short-term recording could be done so the meters were programmed to record the statistics of each thirdoctave bin every minute. A measurement time length of at least 15 minutes, and usually more than 30 minutes, was obtained at each urban location.

For the rural acoustic measurements, a Bruel and Kjaer $12.7 \mathrm{~mm}(0.5$ inch) diameter outdoor microphone was mounted on a tripod at a height of 1.5 meters above the ground surface and connected by a cable to one of the sound level meters residing nearby in a weatherproof box with a large battery. The microphone element, a Model 4189, had a nominal sensitivity of $50 \mathrm{mV} / \mathrm{Pa}$ and was calibrated before use. Sound levels are reported in decibels relative to $20 \mu \mathrm{Pa}$, the standard value customarily used in atmospheric acoustics, so the instrument dynamic range from $10 \mathrm{~dB}$ to $130 \mathrm{~dB}$ corresponds to RMS levels of $64 \mu \mathrm{Pa}$ to $63 \mathrm{~Pa}$. For the urban acoustic measurements, a smaller Norsonic Model 1225 microphone and model 1206 preamplifier mounted directly onto the SLM was used. This $12.7 \mathrm{~mm}$ (0.5 inch) diameter microphone has characteristics similar to the $\mathrm{B} \& \mathrm{~K}$ microphone, but is not weatherproof.

For the seismic measurements, a Mark Products Model L-15 vertical component geophone with a sensitivity of $32 \mathrm{~V} / \mathrm{m} / \mathrm{s}$ and a resonant frequency of $4.5 \mathrm{~Hz}$ was installed at the ground surface near the microphone and was connected to another Norsonic SLM. There is no standard decibel level for seismic measurements, so a reference level of $1 \mu \mathrm{m} \mathrm{s}^{-1}$ was adopted. The seismic measurements using the Norsonic SLM have a dynamic range of $100 \mathrm{~dB}$ to $-20 \mathrm{~dB}$ re $1 \mu \mathrm{m} \mathrm{s}^{-1}$, corresponding to particle velocities of $0.1 \mathrm{~m} \mathrm{~s}^{-1}$ to $0.1 \mu \mathrm{m} \mathrm{s}^{-1}$. However, the dynamic range of 
the geophone will limit the maximum level to about $0.03 \mathrm{~m} \mathrm{~s}^{-1}$ for an actual dynamic range of 90 $\mathrm{dB}$. For the rural measurements, a low-noise preamplifier (Reson Model VP 1000) with a gain of $20 \mathrm{~dB}$ was used to amplify the geophone output before the recording by the SLM. With this amplifier signals as low as $0.01 \mu \mathrm{m} \mathrm{s}^{-1}$ could be measured. Because of the higher expected signal levels, the amplifier was not used during the urban measurements. The authors are not aware of any other studies that have been conducted using a geophone connected to a SLM to measure ambient vibrations.

The geophone was usually attached to the ground surface using a spike approximately $10 \mathrm{~cm}$ long. In urban areas, the geophone could be installed using the spike in a curbside grass patch or at the base of a tree, but in some completely paved locations the spike was replaced with a small triangular base plate to hold the geophone in the correct vertical position. The geophone was designed to measure low frequencies, from $4 \mathrm{~Hz}$ to a few hundred $\mathrm{Hz}$. While the theoretical response of the geophone above the resonant frequency is flat [Sheriff and Geldart, 1995], this response was not tested by the manufacturer and could be affected by mechanical resonances or other factors. No anomalous responses were observed at high frequencies, and the geophone seemed to operate well - when strong enough signals were present - up to a frequency of a few $\mathrm{kHz}$.

Because a tripod could not be used on city streets, the microphone was often placed upright on the ground (about $0.30 \mathrm{~m}$ high) or on a wall or other object. The geophone was installed nearby, and the equipment was never left unattended. The hard ground surface will produce a $+6 \mathrm{~dB}$ increase in the sound pressure level compared to free air measurements, and this effect remains in the reported acoustic pressure values. Previous acoustic noise measurements have shown that positioning a microphone 2 meters or more away from large building facades is sufficient to minimize the effect on the measurement results [Montes González et al., 2015; To et al., 2002], and this was the situation for these measurements. In addition, signal fluctuations arising from the destructive ("ground effect dip") or constructive interference from walls or other objects have a very small effect when integrated over the full width of the third-octave bins, and for moving sources like vehicle traffic.

A tripod-mounted meteorological recorder (Hobo Model 21) was used to record the wind speed, air and ground temperature, relative humidity, and barometric pressure, at one minute intervals during the rural measurements. For the urban measurements, a small USB-based temperature and relative humidity data logger was used (Hobo Model 08), and the wind speed was estimated using a hand-held wind meter.

Aerial maps and the structure of the DoD urban terrain zones were used to choose the measurement sites. The general urban types where measurements were conducted are listed in Table 1. Some effort was made to also find "loud" industrial sites, but with limited success. As will be discussed below, the primary acoustic noise source at nearly all locations was ground transportation noise. 
Table 1. Ambient noise measurement locations and parameters for acoustic and seismic measurements.

\begin{tabular}{|c|c|c|c|c|c|c|c|c|c|c|c|}
\hline \multirow[t]{2}{*}{$\begin{array}{l}\text { Site } \\
\#\end{array}$} & \multirow[t]{2}{*}{ Environment } & \multirow[t]{2}{*}{ Location } & \multirow[t]{2}{*}{$\begin{array}{c}\text { No. } \\
\text { of } \\
\text { sites }\end{array}$} & \multirow[t]{2}{*}{$\begin{array}{l}\text { Distance } \\
\text { (m) }\end{array}$} & \multirow[t]{2}{*}{$\begin{array}{l}\text { Measurement } \\
\text { length (min) }\end{array}$} & \multicolumn{3}{|c|}{$\begin{array}{l}\text { Acoustic } \\
(\mathrm{dB} \text { re } 20 \mu \mathrm{Pa})\end{array}$} & \multicolumn{3}{|c|}{$\begin{array}{l}\text { Vibration } \\
\left(\mathrm{dB} \text { re } 1 \mu \mathrm{m} \mathrm{s}^{-1}\right)\end{array}$} \\
\hline & & & & & & $\begin{array}{l}\text { Leq } \\
\text { (dB) }\end{array}$ & $\begin{array}{l}\text { Max } \\
\text { (dB) }\end{array}$ & $\begin{array}{l}\text { Freq } \\
(\mathrm{Hz})\end{array}$ & $\begin{array}{l}\text { Leq } \\
\text { (dB) }\end{array}$ & $\begin{array}{l}\text { Max } \\
\text { (dB) }\end{array}$ & $\begin{array}{l}\text { Freq } \\
(\mathrm{Hz})\end{array}$ \\
\hline 1 & Rural & Pomfret, VT & 1 & $\sim 200$ & 288 x 5 min. & 39.7 & 45.5 & 6 & -28.1 & -20.8 & 40 \\
\hline 2 & Rural & Lyme, NH & 1 & -- & $288 \times 5 \mathrm{~min}$ & 36.2 & 41.9 & 80 & -23.3 & -16.1 & 16 \\
\hline 3 & City Core & $\begin{array}{l}\text { Baltimore, } \\
\text { MD }\end{array}$ & 2 & $3-5$ & 97 & 71.7 & 77.5 & 80 & 13.5 & 21.2 & 16 \\
\hline 4 & $\begin{array}{l}\text { City } \\
\text { Residential }\end{array}$ & $\begin{array}{l}\text { Baltimore, } \\
\text { MD }\end{array}$ & 2 & $3-5$ & 70 & 63.6 & 69.9 & 63 & 3.0 & 10.8 & 13 \\
\hline 5 & $\begin{array}{l}\text { City } \\
\text { Commercial }\end{array}$ & $\begin{array}{l}\text { Baltimore, } \\
\text { MD }\end{array}$ & 1 & 10 & 35 & 65.6 & 71.6 & 63 & 14.1 & 20.5 & 25 \\
\hline 6 & $\begin{array}{l}\text { City Outlying } \\
\text { High Rise }\end{array}$ & Waikiki, HI & 5 & 10 & 85 & 69.2 & 75.4 & 32 & 12.6 & 20.7 & 10 \\
\hline 7 & $\begin{array}{l}\text { Industrial } \\
\text { Yard } 01 \\
\end{array}$ & $\begin{array}{l}\text { Baltimore, } \\
\text { MD }\end{array}$ & 1 & $50-100$ & 40 & 66.5 & 72.1 & 63 & 17.6 & 25.6 & 6 \\
\hline 8 & $\begin{array}{l}\text { Industrial } \\
\text { Yard } 02\end{array}$ & $\begin{array}{l}\text { Baltimore, } \\
\text { MD }\end{array}$ & 1 & $50-100$ & 34 & 65.1 & 72.1 & 200 & 8.2 & 16.0 & 10 \\
\hline 9 & $\begin{array}{l}\text { City } \\
\text { Construction }\end{array}$ & Waikiki, HI & 1 & 20 & 18 & 83.5 & 95.5 & 63 & 17.7 & 27.1 & 125 \\
\hline & & & & & & & & & & & \\
\hline
\end{tabular}

Notes: The site numbers correspond to those used in the Figures and Appendices.

The distance in column 4 is the estimated distance from the sensors to the main noise source (usually road traffic).

The rural measurements were conducted over an entire 24-hour day at 5-minute intervals; the other measurements were conducted during business hours at one-minute intervals. The Leq values given in column 7 and 10 are for the $6-300 \mathrm{~Hz}$ band.

The distance in column 3 is the approximate distance from the sensors to the main noise source (usually road traffic). The rural measurements were conducted over an entire 24-hour day at 5-minute intervals; the other measurements were conducted during business hours at one-minute intervals. 


\section{Measurement results}

The measurements conducted to characterize the ambient acoustic and seismic noise in rural, urban, and industrial areas are presented in this section. The third-octave Lfeq levels are reported for the acoustic pressure and seismic vibration measurements. Leq is the "equivalent noise level" or time averaged level during a measurement and the " $\mathrm{f}$ " in the symbol indicates that the level refers to a particular third-octave frequency bin. All measurements were unfiltered (or Z-weighted), and the time averaging over the individual recording times was performed directly by the integrating SLM. The time average for the entire measurement period at a site was calculated using

$$
L f e q=10 \log _{10}\left(\frac{1}{N} \sum_{i=1}^{N} 10^{L(i) / 10}\right)
$$

where $N$ is the number of short-time measurement periods, and $L(i)$ the Lfeq value during the short-time period for the frequency bin. To assess the variability of the measurements at a particular site, the standard deviation of the individual frequency Lfeq $(i)$ levels in $\mathrm{dB}$ was also calculated. The measurement locations and parameters are summarized in Table 1.

\subsection{Rural measurements}

Figures 1 and 2 show the measurement results for two different rural sites. Both of these measurements were recorded at 5-minute intervals over a 24 hour period. For these Figures and similar ones that follow, the bars show the time-averaged Lfeq values for each third-octave frequency bin, while the dots indicate the average value \pm twice the decibel standard deviation. For a Gaussian noise distribution, the dots are close to the 5\% and $95 \%$ exceedance levels. The open circles in the acoustic panel are the low wind $(1 \mathrm{~m} / \mathrm{s}) 95 \%$ exceedance levels for an open, rural area determined by Boersma (1997). The $0 \mathrm{~dB}$ level corresponds to $20 \mu$ pascals for the acoustic spectrum, and $1 \mu \mathrm{m} \mathrm{s}^{-1}$ for the vibration spectrum.

The average wind speed for the duration of the rural measurements shown in Figure 1 was 0.8 $\mathrm{m} / \mathrm{s}$, and the lower band of the acoustic noise measurements (black dots) agree with the wind noise model of Boersma (1997) for frequencies up to $80 \mathrm{~Hz}$. Above this frequency, the measurements have higher noise levels, with a small peak near $100 \mathrm{~Hz}$. This high frequency level might be caused by wind noise from a spruce forest stand located about $150 \mathrm{~m}$ from the measurement site. Comparing the spectrum from this location with the spectrum from the other rural location shown in Figure 2 reveals a slight increase near $100 \mathrm{~Hz}$ at the second location, and generally lower acoustic levels closer to the $1 \mathrm{~m} / \mathrm{s}$ wind speed model of Boersma (1997). The vibration measurements show very low levels, differing in details, at both locations. 

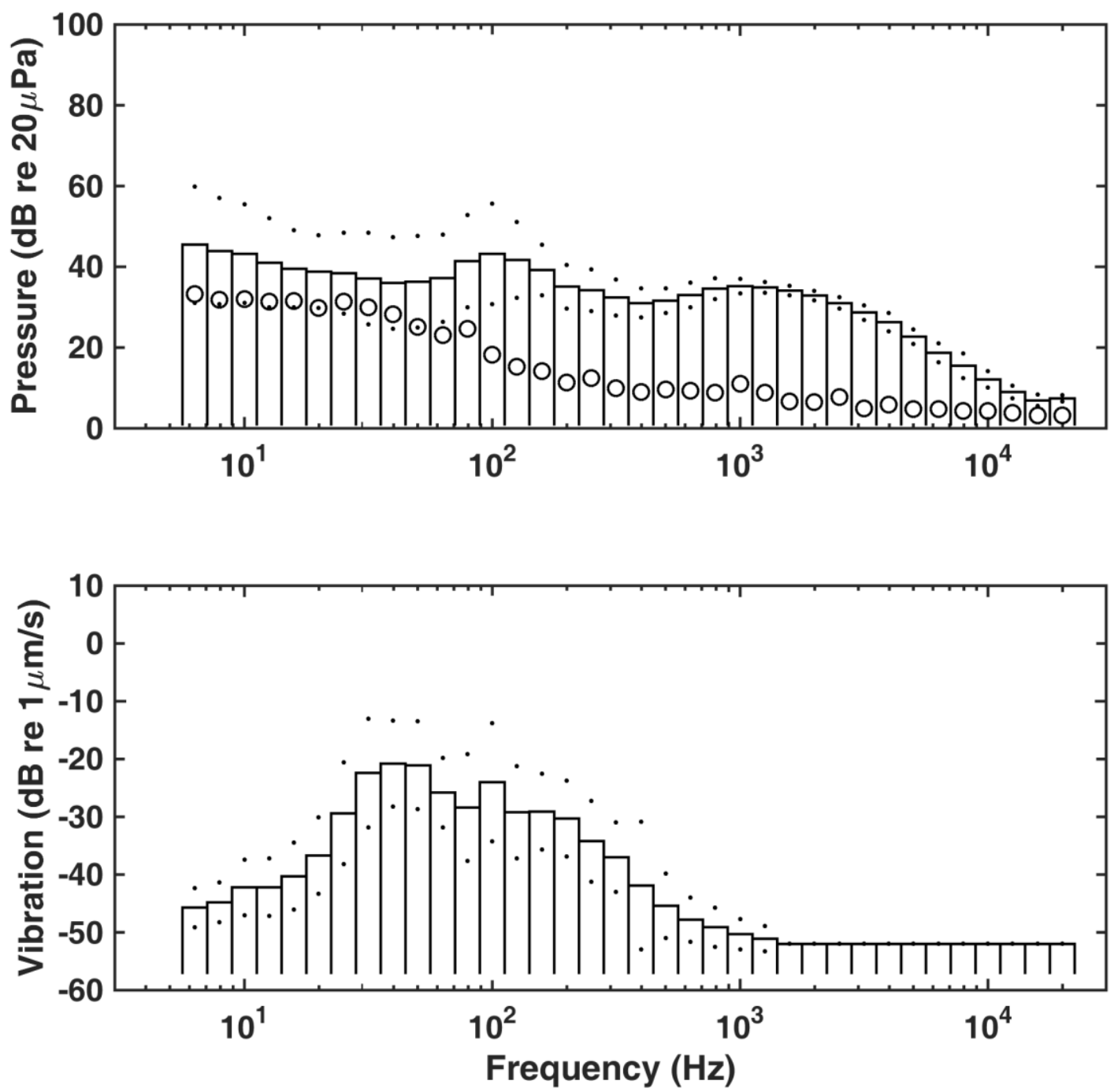

Figure 1. One-third octave Lfeq measurements at a rural location near Pomfret, Vermont for a full 24-hour period. (Top) Acoustic Lfeq spectrum. The bars are the time-averaged Lfeq values for each frequency bin, while the dots indicate the average value \pm twice the decibel standard deviation. Circles are the low wind $(1 \mathrm{~m} / \mathrm{s})$ 95\% exceedance levels in an open, rural area (Boersma, 1997). The measured wind speed during the acoustic measurements was $0.8 \mathrm{~m} / \mathrm{s}$. (Bottom) Vibration Lfeq spectrum, showing very low vibration levels at this site. The 0 dB level corresponds to $20 \mu$ pascals for the acoustic spectrum, and $1 \mu \mathrm{m} \mathrm{s}^{-1}$ for the vibration spectrum. 

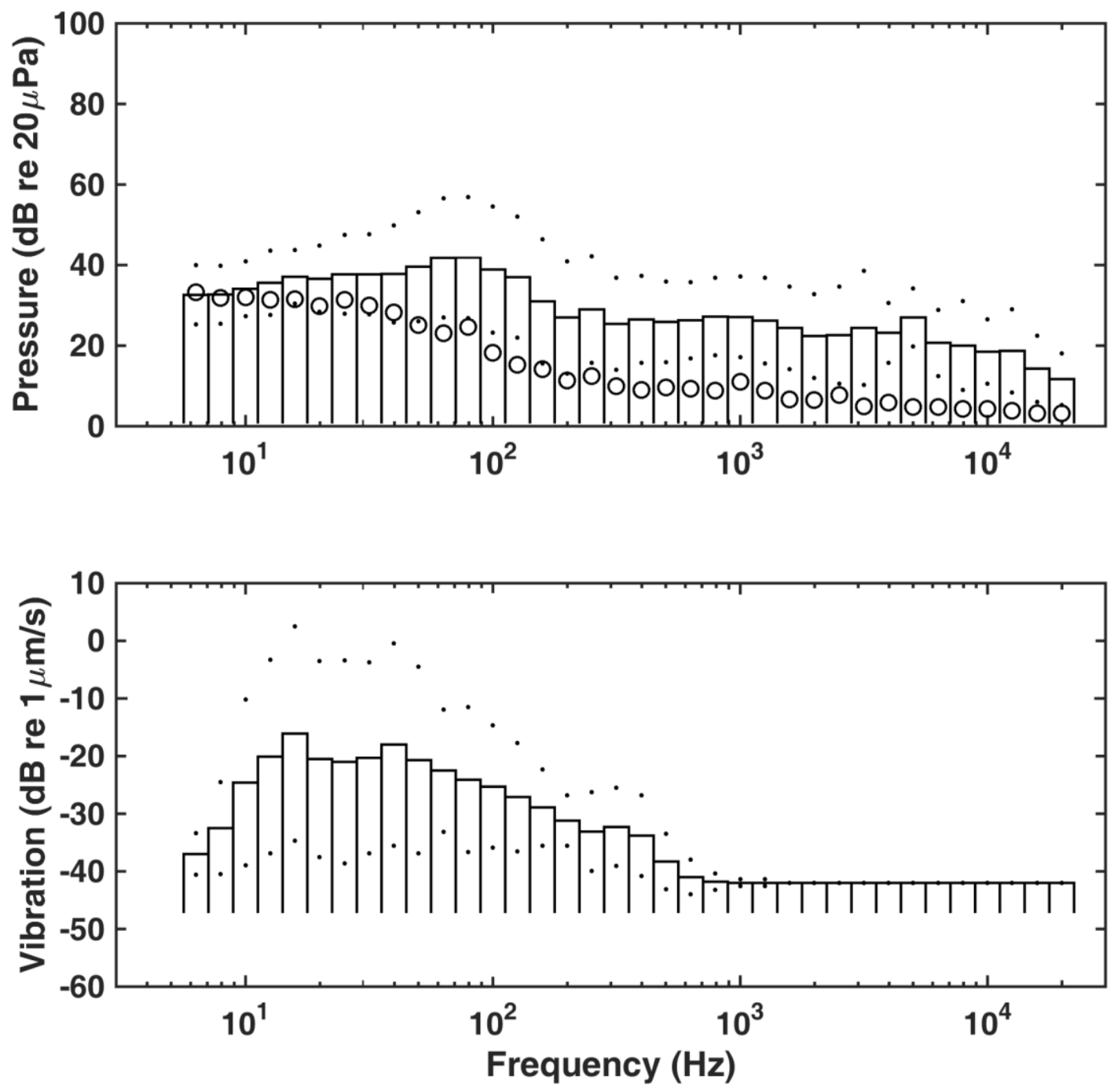

Figure 2. One-third octave Lfeq measurements at a rural location near Lyme, New Hampshire for a full 24-hour period. (Top) Acoustic Lfeq spectrum using the same symbols as in Figure 2. (Bottom) Vibration Lfeq spectrum. The $0 \mathrm{~dB}$ level corresponds to $20 \mu$ pascals for the acoustic spectrum, and $1 \mu \mathrm{m} \mathrm{s}^{-1}$ for the vibration spectrum.

\subsection{Rural diurnal variations}

Because background noise varies diurnally due to human activities ("cultural noise"), it would be best to record at least one full day at each measurement site to characterize this variation. This was possible for the rural locations, but not in urban or industrial areas.

The US Environmental Protection Agency (EPA) uses a $10 \mathrm{~dB}$ adjustment to A-weighted acoustic measurement as a nighttime difference for data recorded between the hours of 10 PM and $7 \mathrm{AM}$, while other regulatory agencies recommend a 5 or a $10 \mathrm{~dB}$ adjustment for nighttime measurements. However, while these adjustments may serve as a guide to the actual variation in 
noise levels at night, they are used to predict the annoyance experienced by civilian populations, and so they are intended to estimate human response effects rather than the actual sound level. Previous seismic measurements do not report day/night differences since most published measurement sites are selected to be at the lowest noise level possible, and are ordinarily located far from roads or other cultural noise sources. In addition, cultural noise levels are relatively low for seismic frequencies near and below $1 \mathrm{~Hz}$.
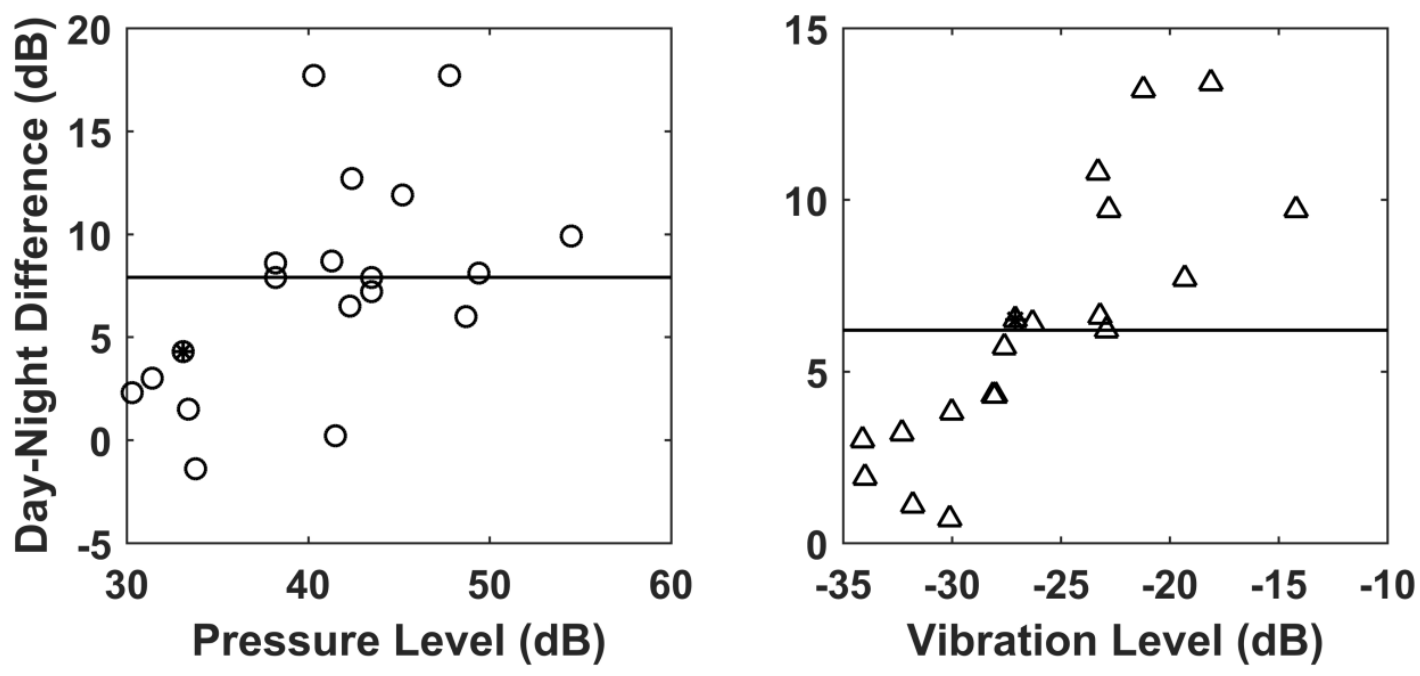

Figure 3. Measured acoustic (left) and seismic (right) day-night Leq level differences integrated over the $6.3-300 \mathrm{~Hz}$ frequency band. Nighttime hours were 10 PM to 7 AM. A total of 19 measurement days are included. Results for the measurement day shown in Figure 2 are indicated by the filled symbols. The median difference over 19 days is indicated by the horizontal lines at 7.9 and $5.2 \mathrm{~dB}$, respectively, for the acoustic and vibration levels.

To estimate the day-night difference in rural areas, 19 full measurement days (midnight to midnight) were recorded and analyzed at the Pomfret, Vermont site. A frequency band of 6.3 $300 \mathrm{~Hz}$ was selected for this analysis to allow for direct comparisons between the acoustic and seismic variations and because this low frequency band is the most important one for most military sensor systems. Day-night differences of $6-8 \mathrm{~dB}$ were measured for both of the sensors (see Table 2 and Figure 3). These measurements agree with the $5-10 \mathrm{~dB}$ adjustments for acoustic variations in various regulations. However, because the noise levels in rural areas are only partially determined by traffic noise (the dominant noise source in urban areas), the daynight variation in levels may be quite different in urban areas. 
Table 2. Rural acoustic and seismic day-night integrated Leq differences for the $6.3-300$ Hz band.

\begin{tabular}{|l|c|c|c|c|}
\hline Type & Median & $\begin{array}{l}\text { Standard } \\
\text { deviation }\end{array}$ & Maximum & Minimum \\
\hline Acoustic $(\mathrm{dB}$ re $20 \mu \mathrm{Pa})$ & 7.9 & 5.2 & 17.7 & -1.4 \\
\hline Seismic $(\mathrm{dB}$ re $1 \mu \mathrm{m} / \mathrm{s})$ & 6.2 & 3.8 & 13.4 & 0.7 \\
\hline & & & & \\
\hline
\end{tabular}

\subsection{Urban noise measurements}

The U.S. Department of Defense has developed a system of Urban Terrain Zones (UTZ) to categorize city locations for use in modeling and simulation studies. The categories depend on the cultural activities and morphology of the area, including street width, building height and dimensions, building density, and other factors determined by a series of city surveys [Ellefsen, 1987]. These descriptive categories and aerial photographs were used to guide the selection the measurement locations used in this study.

Ambient noise measurements were conducted at various urban locations in Waikiki, HI and Baltimore, MD to obtain a noise database for the urban terrain zones. Figure 4 displays photographs of some of the urban measurement locations. Because of security concerns and other problems operating in an urban area, the measurements were limited to short time periods of an hour or less. In addition, budgetary and other constraints limited the urban measurements to only three days. In an effort to reduce the variation from different traffic levels, all measurements were conducted on weekdays during normal business hours while avoiding rush hour periods. In some cases (city core zone) similar locations (with similar spectra) were combined to extend the measurement time and improve estimates of spectral variability.

The one-third octave urban acoustic and vibration spectra from two of the urban zones are shown in Figures 5 and 6, and these measurements represent the highest and lowest levels for urban areas with normal cultural activities. (The highest noise levels were measured at construction sites that will be discussed below). For the acoustic measurements, the spectra tend to have the same general shape for different urban zones, within a variation of approximately $15 \mathrm{~dB}$ for frequencies up to $10 \mathrm{kHz}$. The peak level occurs around $100 \mathrm{~Hz}$, and decays with increasing frequency by $10-15 \mathrm{~dB}$ at $1 \mathrm{kHz}$. The acoustic noise levels are still measureable at the upper instrument limit of $20 \mathrm{kHz}$. The urban acoustic levels are $20-30 \mathrm{~dB}$ higher than the rural levels at all frequencies, and extend to about $1 \mathrm{kHz}$ before reaching the instrument self-noise limit (see Appendix A). 

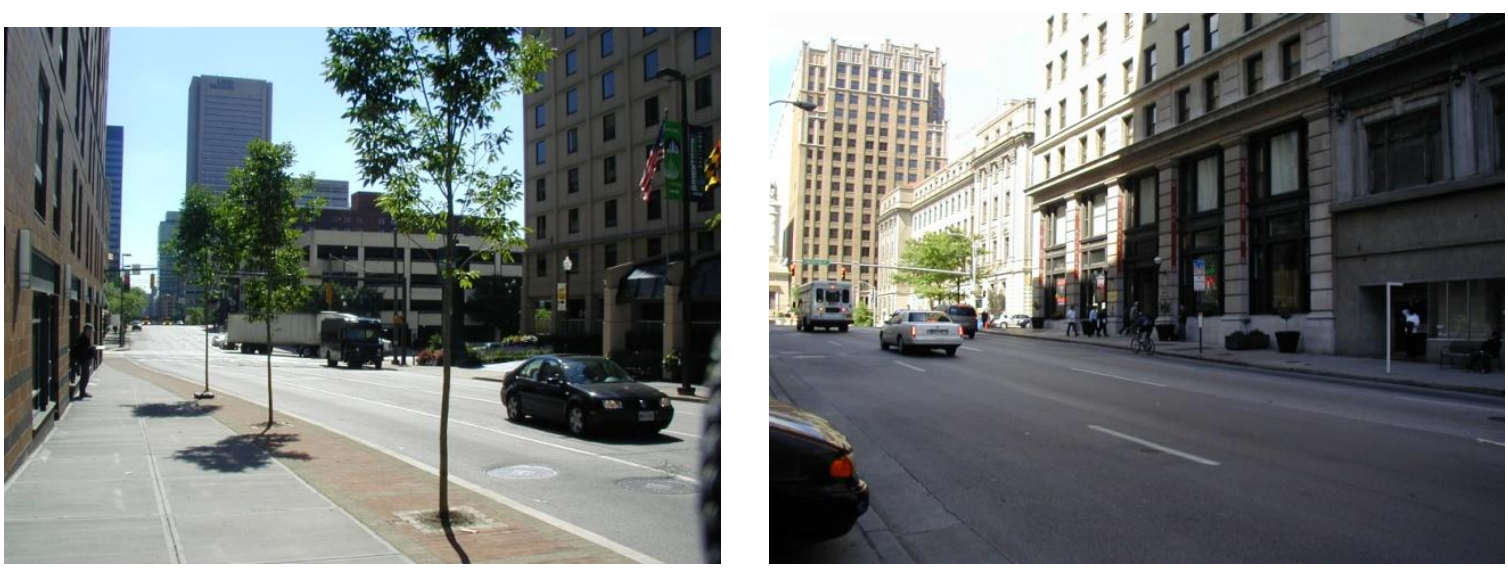

Figure 4. (color online) Two urban city core measurement locations (Site 3) in Baltimore, MD.
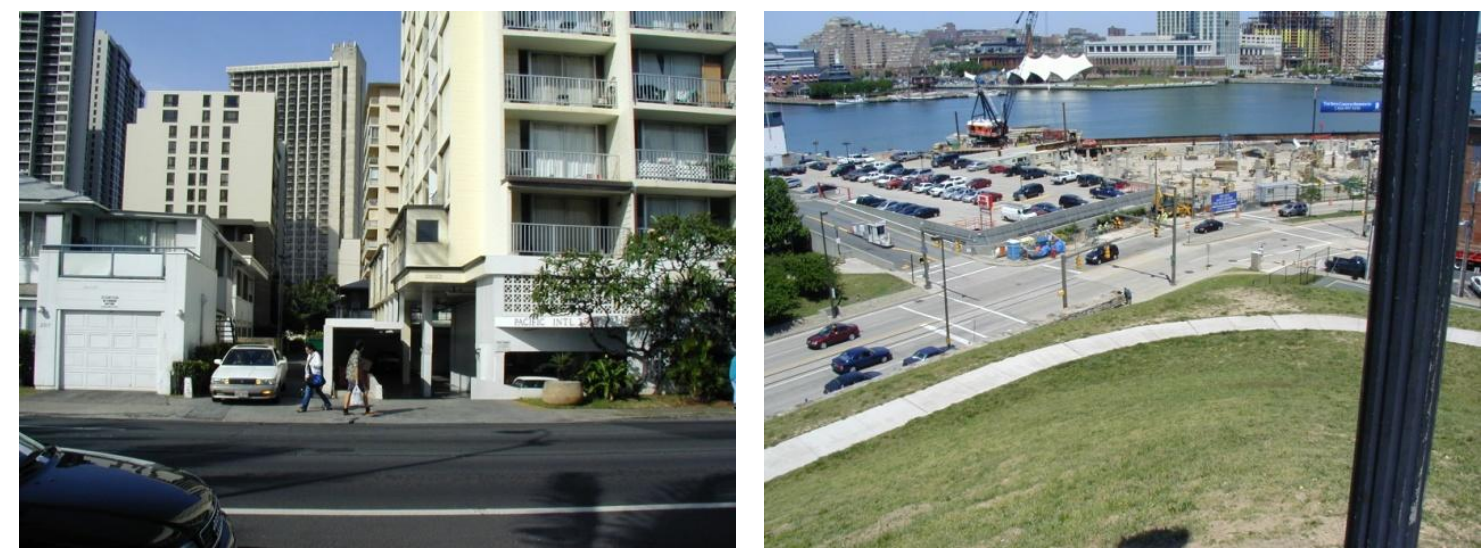

Figure 4, continued. (Left) Outlying high rise area (Site 6) in Waikiki, HI, and (right) commercial area (Site 5) in Baltimore, MD.
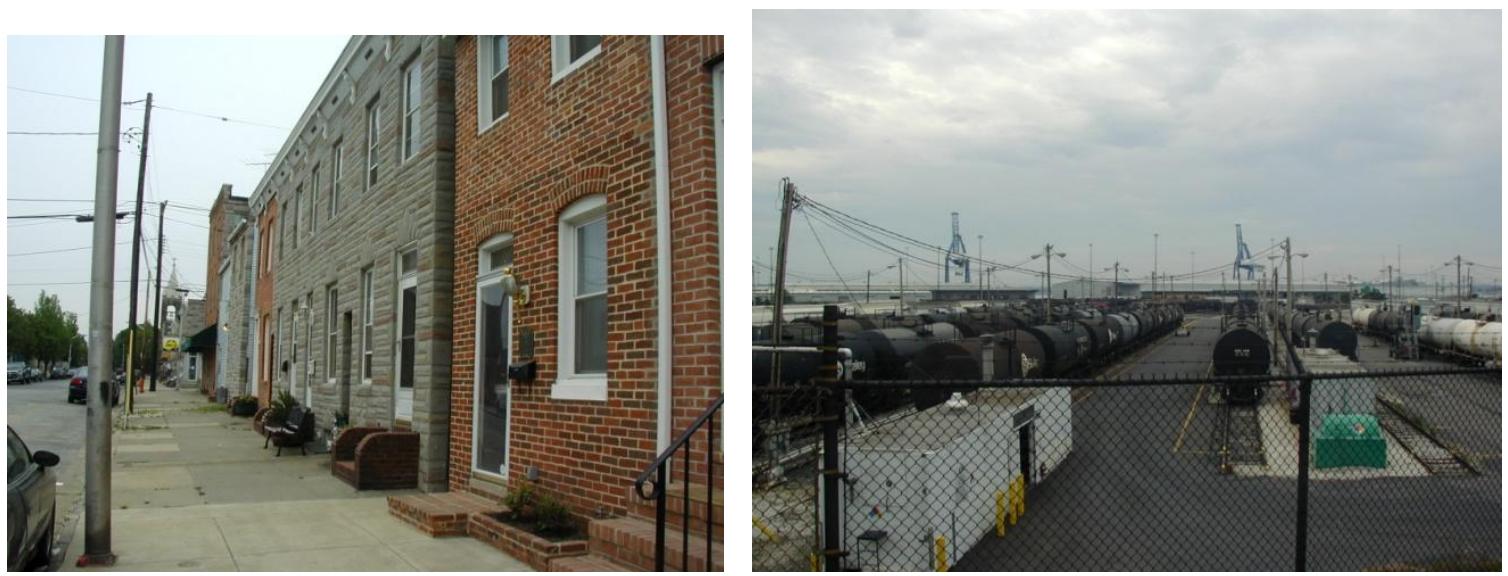

Figure 4, continued. (Left) Urban residential area (Site 4) and (right) industrial yard area (Site 8) in Baltimore, MD. 

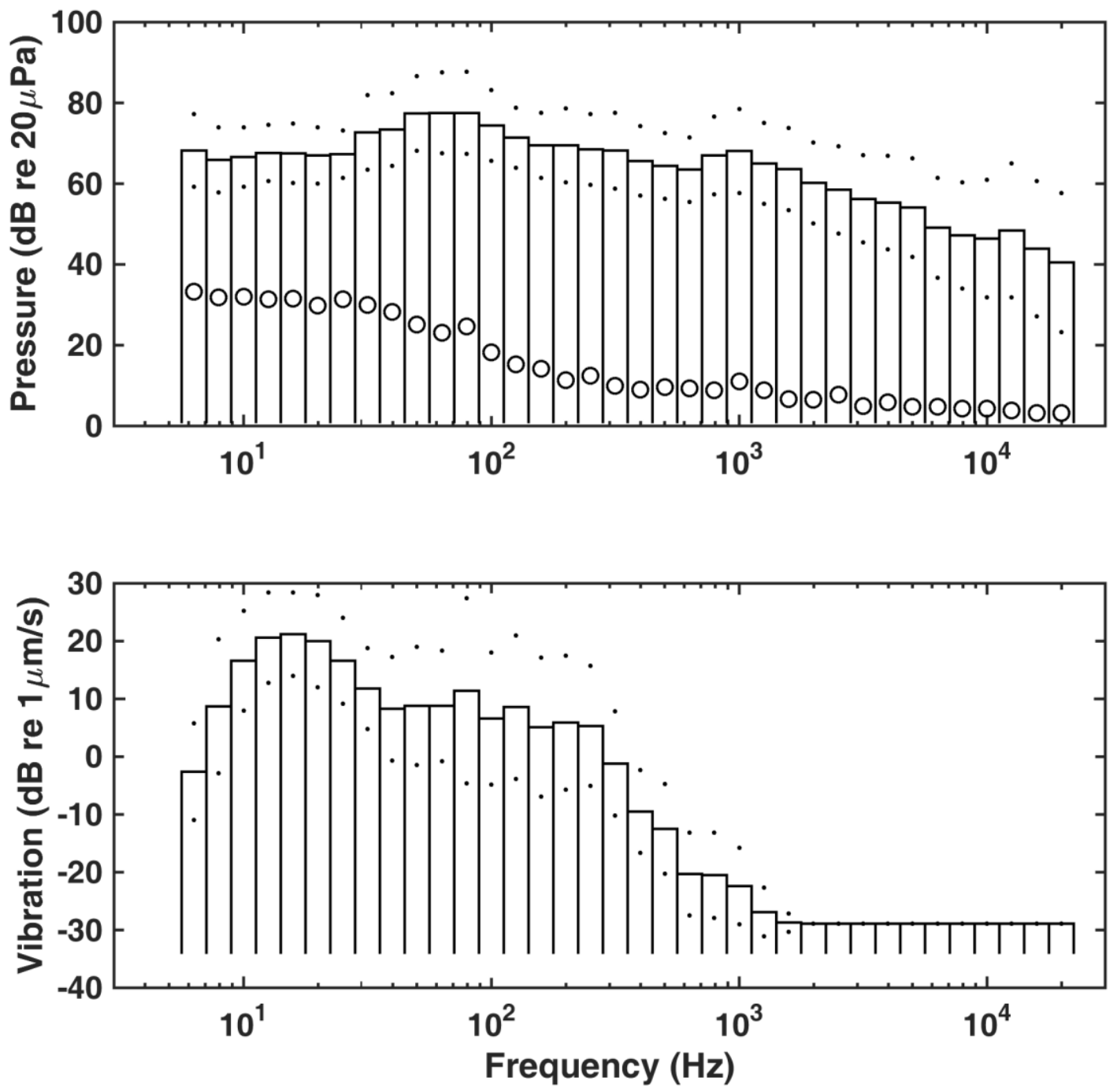

Figure 5. One-third octave Lfeq measurements in urban city cores (Site 3) recorded at 1 minute intervals. (Top) Acoustic Lfeq spectrum. Circles are the low wind $(1 \mathrm{~m} / \mathrm{s}) 95 \%$ exceedance levels in an open, rural area (Boersma, 1997). (Bottom) Vibration Lfeq spectrum. The $0 \mathrm{~dB}$ level corresponds to $20 \mu$ pascals for the acoustic spectrum, and $1 \mu \mathrm{ms}^{-1}$ for the vibration spectrum. These measurements were made at two separate central city locations. 

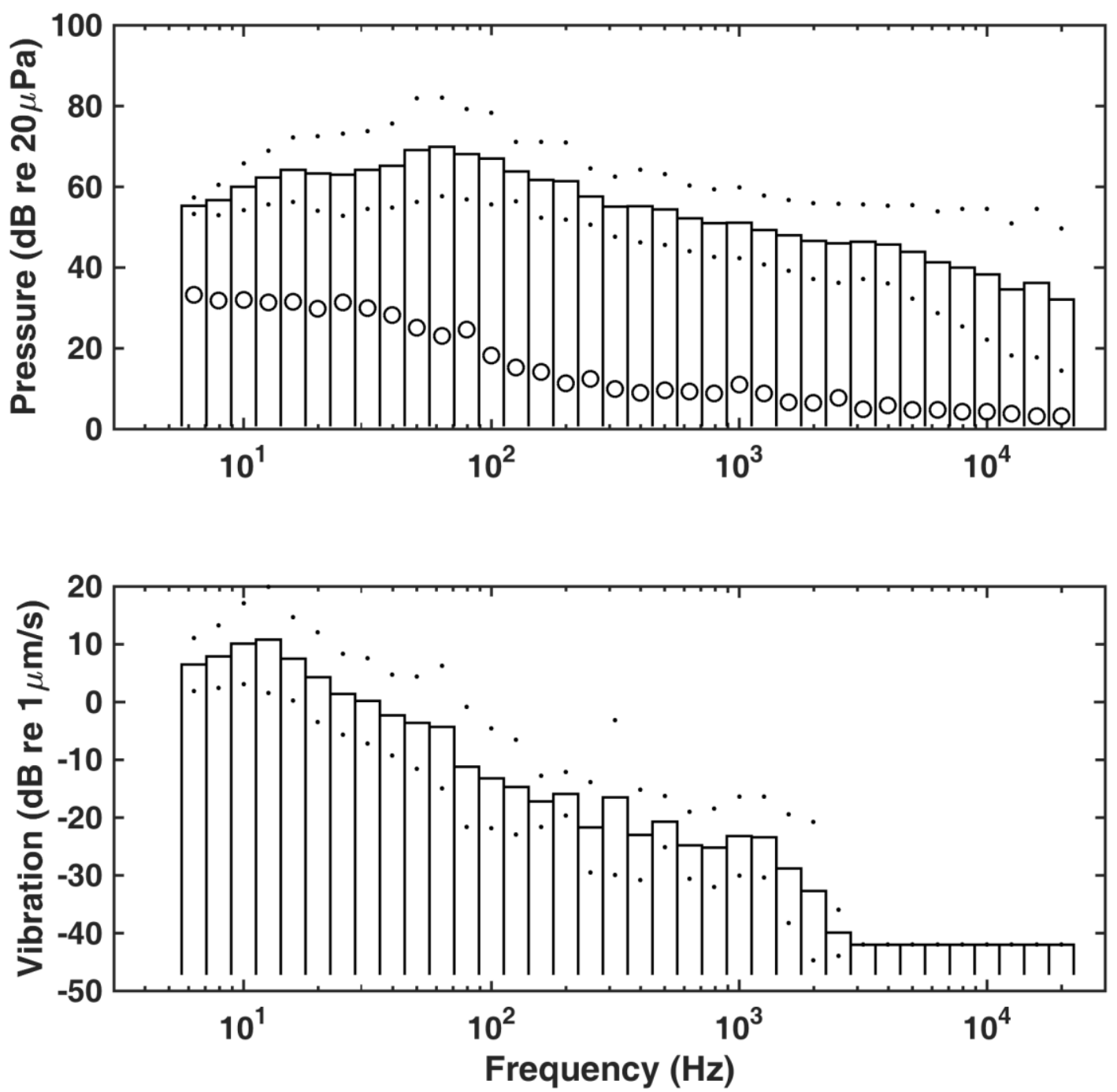

Figure 6. One-third octave Lfeq measurements at two urban residential locations (Site 4) with attached 2 and 3 story row houses. (Top) Acoustic Lfeq spectrum. Circles are the low wind (1 $\mathrm{m} / \mathrm{s}$ ) 95\% exceedance levels in an open, rural area (Boersma, 1997). (Bottom) Vibration Lfeq spectrum.

The overall spectral shapes are more variable for the vibration spectra than for the acoustic spectra, with peak frequencies ranging from 6 to $30 \mathrm{~Hz}$. The vibration spectra decrease by about $30 \mathrm{~dB}$ as the frequency increases from $30 \mathrm{~Hz}$ to $1 \mathrm{kHz}$, and the ambient noise at higher frequencies is usually below the instrumentation noise level as discussed earlier. The variation from one urban terrain type to another is about $10-15 \mathrm{~dB}$ at each frequency, and the vibration levels are about $30-40 \mathrm{~dB}$ higher than those measured in rural areas. 
The acoustic and seismic spectral shapes and peak frequencies are consistent with previous measurements of vehicle spectra[Riahi and Gerstoft, 2015]. While making the measurements, it
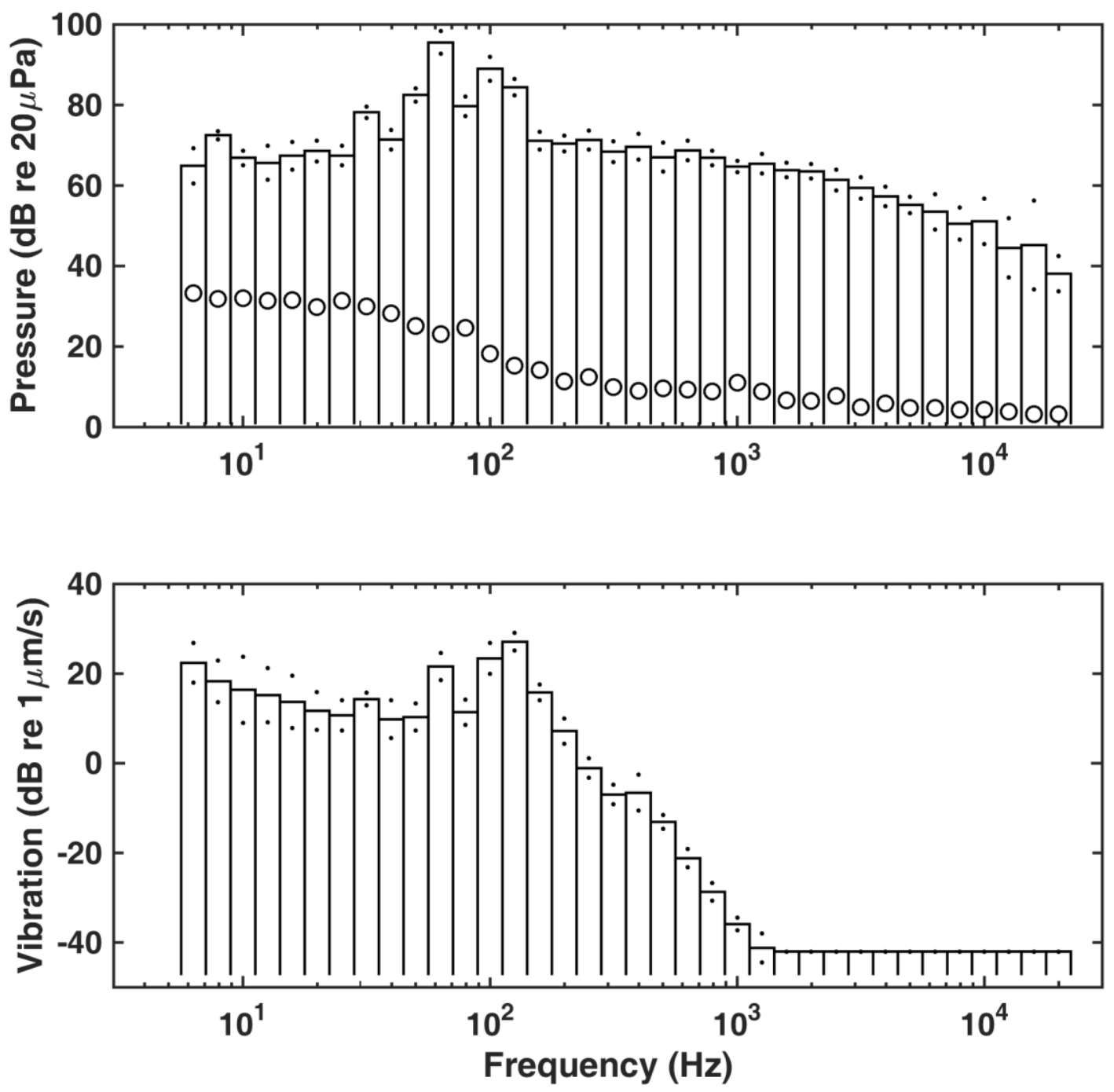

Figure 7. One-third octave Lfeq measurements at Site 9, an urban location with heavy deconstruction activity. Slow moving traffic and jack hammer activity contributed to the noise spectra. (Top) Acoustic Lfeq spectrum. Circles are the low wind $(1 \mathrm{~m} / \mathrm{s}) 95 \%$ exceedance levels in an open, rural area (Boersma, 1997). (Bottom) Vibration Lfeq spectrum.

[ApplAcoustics2007AlbertAmbientNoiseFiguresOnlyVer02.doc]

was observed that most of the acoustic noise was produced by transportation sources, in agreement with previous A-weighted acoustic studies for civilian annoyance. This finding also holds for the vibration results, although the peak vibration frequencies generated by vehicles with mufflers tend to be lower than for the acoustic measurements, around $10-30 \mathrm{~Hz}$. Even in relatively quiet urban residential areas with infrequent nearby traffic, traffic noise from the 
nearest large road (or high-speed freeway up to a few $\mathrm{km}$ away) was still audible and likely responsible for the noise to remain above a threshold level of about $20 \mathrm{~dB}$.

Loud industrial noise sources are not common in the United States and many other countries due to environmental regulations. Often the main noise source at an industrial location was from traffic, not from industrial machinery or activities. In this survey the loudest noise levels were found at construction sites, and the loudest spectra are shown in Figure 7 at a high-rise building being constructed. Both the acoustic and seismic spectra show a "rougher" shape than the other spectra with some individual spectral lines at frequencies below $125 \mathrm{~Hz}$. These spectral lines are likely produced by the large dump trucks (on bumpy ground), a pile driver, and circular saws that were observed or heard operating at the site. The very low variability of the measurements (indicated by the black dots on Figure 7) are also indicative of steady, local sources producing the noise at this location, instead of typical traffic noise that tends to be more intermittent.

Peak frequency information for two other industrial sites are reported in Table 1. Site 7 was near a railroad yard with an operating diesel locomotive switching freight cars, and exhibited very strong low frequency seismic vibrations. Site 8 was an intermodal yard where loads were transferred from railroad cars to trucks. In this case, a blower was operating to remove granular material from a railroad tank car to a truck. The acoustic noise was loud and similar to a home vacuum cleaner. The seismic noise was likely produced by car traffic along the street about 10 $\mathrm{m}$ from the sensors; the yard was protected by a fence so the blower was about $100 \mathrm{~m}$ away.

As mentioned previously, diurnal measurements in these urban areas were not possible. The diurnal variation is not expected to follow a pattern similar to rural areas because of the very different traffic patterns. While city traffic does decrease at night, traffic never stops completely, so the urban levels are likely to always remain higher than those measured for the rural areas. A reasonable estimate of the lowest expected urban noise levels might be a spectrum within a few $\mathrm{dB}$ of the urban residential measurements, since the transportation noise from distant highways would still be received at any urban location. The urban noise pattern at night might depend more strongly on proximity to a main thoroughfare or highway instead of the local traffic flow during business hours. Industrial noise sources are expected to show more variability, and may revert to traffic noise levels intermittently (as with construction sources that start and stop every few minutes) or during non-work hours.

\subsection{Comparison of the urban and rural measurements}

Figures 8 and 9 present all of the measured spectra for comparison. The rural acoustic spectra are generally about $20 \mathrm{~dB}$ lower than any of the urban spectra, and both types of measurements show relatively smooth spectra that decrease in amplitude as the frequency increases. The variation in amplitude between different urban zones for individual frequency bins is about $10-$ $20 \mathrm{~dB}$. Most of the urban acoustic noise was produced by vehicle traffic on nearby roads.

By replacing the microphone with a geophone, ground vibration measurements were successfully recorded over a frequency band from $6 \mathrm{~Hz}$ to a few $\mathrm{kHz}$. The urban seismic spectra also are relatively smooth and show a general decrease in level with increasing frequency. All of the urban measurements were $10-30 \mathrm{~dB}$ higher than the rural measurements at the same frequency. 


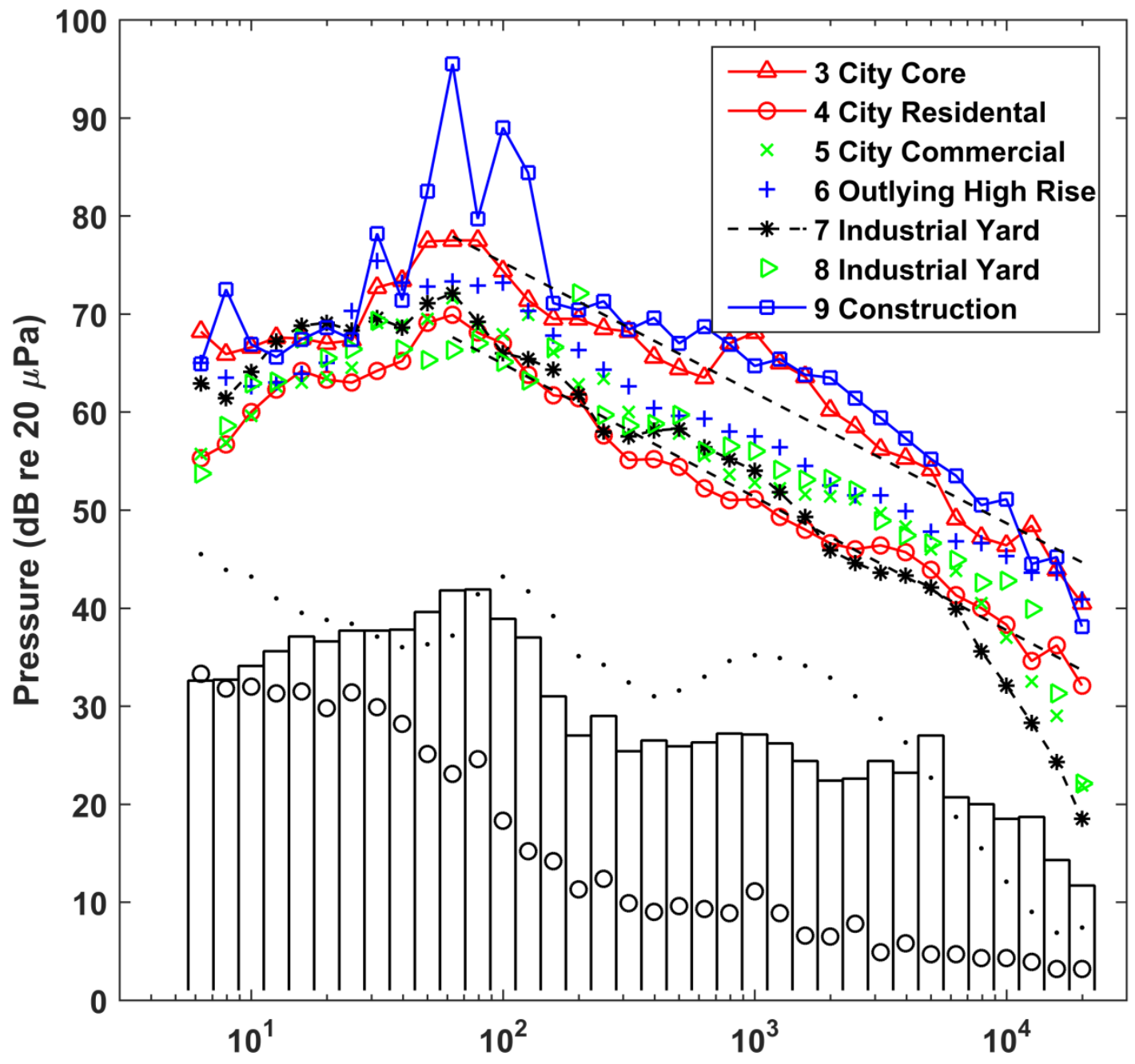

Figure 8. (Color online) One-third octave acoustic noise levels for the urban and rural locations. The various urban measurements are identified in the legend; construction noise is generally the loudest followed by city core measurements with heavy traffic; the lowest levels are for city residential areas. The rural measurements are shown by black dots (for Site 1) and by the bar graph (for Site 2). Boresma's (1997) wind noise measurements for $1 \mathrm{~m} / \mathrm{s}$ is indicated by open circles. Dashed lines are regression lines for the urban core and residential measurements (see Table 2).

The highest third-octave noise levels for both acoustic and seismic measurements were measured at a construction site with heavy operating equipment as well as hand tools. At this location the highest levels were produced by machinery in the $50-160 \mathrm{~Hz}$ band of frequencies. When industrial noise does exceed the traffic noise, the source spectra tend to be more variable as machines tend to produce stronger output at specific frequencies related to motor-driven rotation rates. In addition, machine activities that start and stop will also cause more variation in the overall noise levels. 


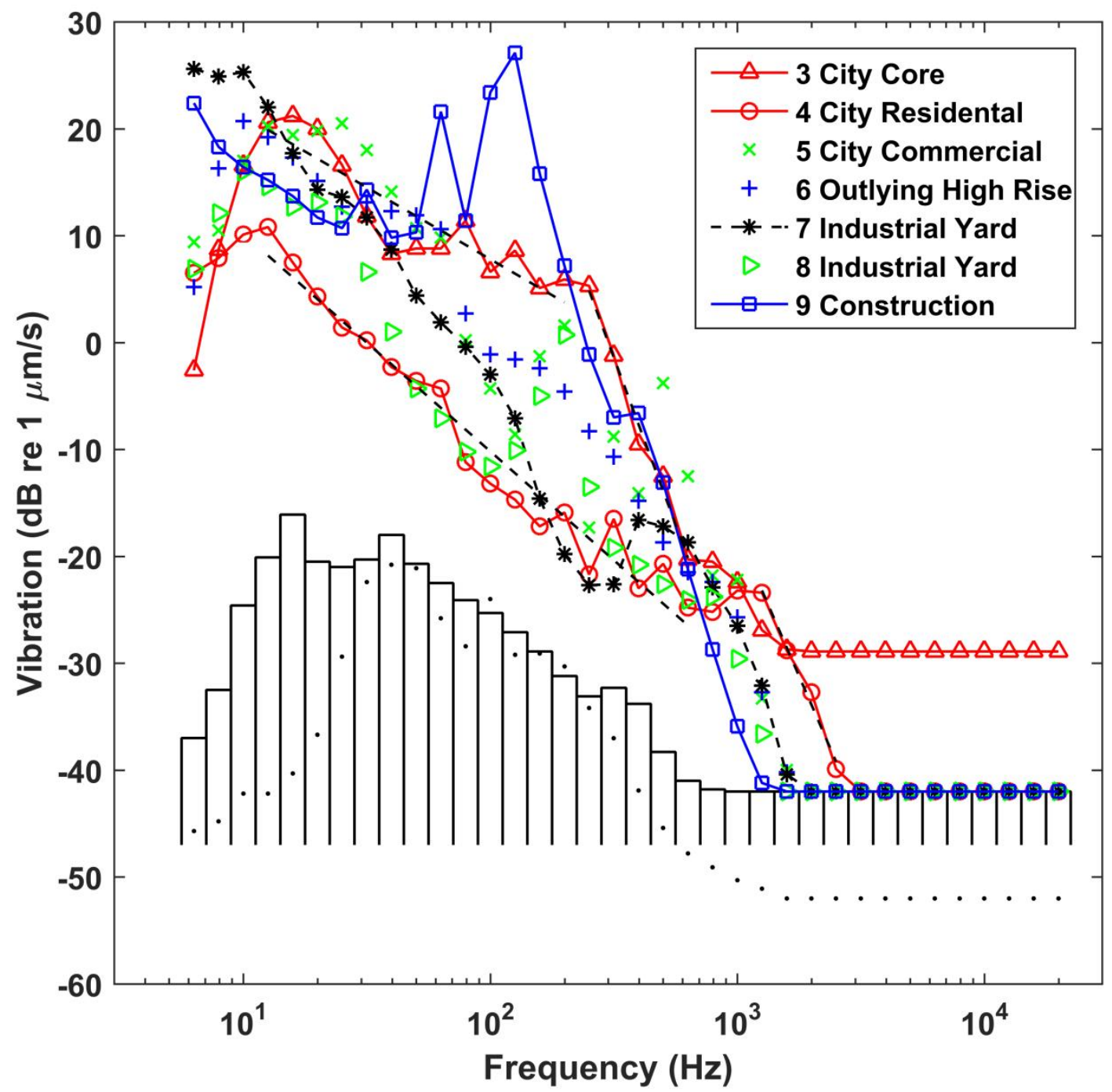

Figure 9. (Color online) One-third octave seismic noise levels for the urban and rural locations. Same symbols as for Figure 8. Dashed lines are regression lines for the urban core and residential measurements (see Table 2).

The measurements show that the noise levels in non-industrial urban zones were bounded by the higher urban core zones and the lower urban residential zones, so these two zones indicate the range of expected levels of ambient noise in urban areas, at least for cities in the United States. The results may change at other locations if the vehicle mix changes. For example, cities with more heavy trucks or motorcycle-based vehicles would likely have increased noise levels.

For the acoustic pressure measurements, the peak noise level occurs in the $32-80 \mathrm{~Hz}$ band, and ranges from 74 to $64 \mathrm{~dB}$ for the urban core and residential zones, respectively (see Table 1 and Figure 8). As the frequency increases above the peak frequency, the sound levels decrease. A 
least squares fitting procedure was applied to these higher frequency bands for the urban sites 3 and 4 and resulted in the following equations:

$$
\begin{aligned}
& P 3(\mathrm{~dB})=-13.3 \log _{10}(f)+101.2 \text { for the city core measurements, and } \\
& P 4(\mathrm{~dB})=-13.6 \log _{10}(f)+92.1 \text { for the city residential measurements. }
\end{aligned}
$$

In the above equations, $P 3$ and $P 4$ give the third-octave equivalent noise level for sites 3 or 4 in $\mathrm{dB}$ re $20 \mu \mathrm{Pa}$, and $f$ is the third-octave center frequency in $\mathrm{Hz}$. These equations were derived for the frequency band from $60 \mathrm{~Hz}$ to $20 \mathrm{k} \mathrm{Hz}$. The regression line slope of $-13 \mathrm{~dB}$ per decade is slightly larger than an $\mathrm{f}^{-1 / 2}$ decay rate with increasing frequency. As shown in Figure 8 , the regression lines roughly bracket the audible traffic noise measurements in the different urban areas.

Table 2. Regression line parameters derived from the urban core and urban residential measurements, where $P d B=a \log 10(f)+b$.

\begin{tabular}{|l|l|c|c|c|}
\hline Type & $\begin{array}{l}\text { Urban } \\
\text { location }\end{array}$ & $\begin{array}{c}\text { Frequency band } \\
(\mathrm{Hz})\end{array}$ & $a$ & $b$ \\
\hline Acoustic $(\mathrm{dB}$ re $20 \mu \mathrm{Pa})$ & $3-$ core & $60-20 \mathrm{k}$ & -13.3 & 101.8 \\
\hline & 4 - residential & $60-20 \mathrm{k}$ & -13.6 & 92.1 \\
\hline & & & & \\
\hline Seismic $(\mathrm{dB}$ re $1 \mu \mathrm{m} / \mathrm{s})$ & 3 - core & $12.5-200$ & -13.4 & 34.7 \\
\hline & 3 - core & $250-630$ & -62.5 & 154.9 \\
\hline & 4 - residential & $12.5-630$ & -20.6 & 30.5 \\
\hline & 4 - residential & $1250-2500$ & -53.4 & 142.4 \\
\hline & & & & \\
\hline
\end{tabular}

With the exception of the construction work site, the seismic peak frequencies for the urban locations are in the 6 to $25 \mathrm{~Hz}$ band and are lower than the acoustic peak frequencies. The peak urban vibration levels range between 3 and $18 \mathrm{~dB}$ re $1 \mu \mathrm{m} / \mathrm{s}$. Excluding the industrial and construction sites, the frequency midrange of urban sites is roughly bounded by the urban core and residential sites (sites 3 and 4). For these sites the measurements show a relatively low attenuation rate at frequencies below a few hundred $\mathrm{Hz}$, and with a larger decay rate at higher frequencies, so two separate regression line segments were derived using the least squares method. The regression line parameters are listed in Table 2. In the low frequency band, a decay rate of -13 or $-20 \mathrm{~dB} /$ decade was determined for the two sites. The low-frequency attenuation rate for the urban core was similar to the acoustic rate, while the residential area rate was higher at $-20 \mathrm{~dB}$ per decade, or approximately $1 / \mathrm{f}$. At the higher frequencies the attenuation rate was much higher, -62 and $-53 \mathrm{~dB}$ per decade respectively, close to $\mathrm{f}^{-3}$.

\section{Concluding remarks}

Measurements characterizing seismic and acoustic ambient noise and their variability have been obtained in rural and urban areas. In urban areas these measurements are controlled primarily by vehicle traffic patterns, and the seismic spectra exhibit much more variation from one zone to 
another than the acoustic spectra. The third-octave ambient noise measurements provide a necessary component for use in sensor performance simulations, allowing open field wind effects, rural areas, and a number of urban environments to be included in these predictions.

While the motivation for these measurements was for sensor applications, these measurements might also provide some information of use in studies of human response. The acoustic measurements can easily be converted to A-weighting for human response studies, and the sound levels were quite audible. The measured sounds might provide a useful representation of annoying sounds that mask desired sounds for soundscape planning and design, e.g. [Kang, 2006; Rehan, 2015].

In terms of human perception, the urban traffic noise at all locations was audible and identifiable, and well above perception thresholds. For vibration, the pile driver at the construction site was perceptible, but was not accurately captured in the measurements because of the impulsive nature of the signal. The highest measured vibration levels from industrial or construction sites approached $30 \mathrm{~dB}$ re $1 \mu \mathrm{m} / \mathrm{s} \sim 32 \mu \mathrm{m} / \mathrm{s}=0.032 \mathrm{~mm} / \mathrm{s}$ particle velocity, while the peak traffic noise in the urban core was $18.9 \mathrm{~dB}$ or $8.8 \mu \mathrm{m} / \mathrm{s}$ at $12.5 \mathrm{~Hz}$. At $80 \mathrm{~Hz}$ the highest levels were $8-$ $10 \mathrm{~dB}$ for traffic or industrial noise, equivalent to $2.5-3 \mu \mathrm{m} / \mathrm{s}$. ANSI standard S2.71 [1983] gives human perception levels for particle velocity in its Table 1 , and the lowest value is $1 \times 10^{-4}$ $\mathrm{m} / \mathrm{s}$ for the frequency range $8-80 \mathrm{~Hz}$. This value converts to $40 \mathrm{~dB}$ re $1 \mu \mathrm{m} / \mathrm{s}$, well above the of traffic noise measurements presented here.

\section{Acknowledgements}

This research was funded by a grant from the Urban Operations Focus Area Collaborative Team (UO FACT) and by ERDC applied research projects. We thank Frank E. Perron, Jr. for assistance with the rural noise measurements in Pomfret, VT, and Mr. Leon Stetson for allowing us to use the Pomfret site. Unpublished oral presentations by Mr David F. Fordyce and Ms. Kathy Luft of USAMSAA (US Army Materiel Systems Analysis Activity) on urban terrain zones were helpful to our understanding of this categorization system. We also thank the two anonymous reviewers for their helpful comments. Permission to publish was granted by the Director, Cold Regions Research and Engineering Laboratory.

\section{References}

Ambrose, S. (2006), Sandhill Company; Sound Levels in the Primary Vegetation Types in Grand Canyon National Park, July 2005 Rep., NPS Report No. GRCA-05-02.

American National Standards Institute (1983, reaffirmed 2012), Guide to the evaluation of human exposure to vibration in buildings, ANSI S2.71-1983 (R2012), Melville, NY, 12 pp.

Banerji, S. K. (1924), Microseisms associated with the incidence of the south-west monsoon, Nature, 114-2868, 576.

Barstow, N., J. A. Carter, P. W. Pomeroy, and G. H. Sutton (1990), High frequency (1 - 100 Hz) noise and signal recorded at different depths in a mine, northwest Adirondacks, NY, Geophysical Research Letters, 17, 681-684.

Becker, G., and A. Gudesen (2000), Passive sensing with acoustics on the battlefield, Applied Acoustics, 59, 149-178. 
Behm, M., G. M. Leahy, and R. Snieder (2014), Retrieval of local surface wave velocities from traffic noise-an example from the La Barge basin (Wyoming), Geophysical Prospecting, 62(2), 223-243.

Berger, J., H. K. Eissler, F. L. Vernon, I. L. Neresov, M. B. Gokhberg, O. A. Stolyrov, and N. T. Tarasov (1988), Studies of high-frequency noise in eastern Kazakhstan, Bulletin of the Seismological Society of America, 78, 1744-1758.

Boersma, H. F. (1997), Characterization of the natural ambient sound environment: Measurements in open agricultural grassland, The Journal of the Acoustical Society of America, 101(4), 2104-2110.

Bormann, P. (1998), Conversion and comparability of data presentations on seismic background noise, Journal of Seismology, 2(1), 37-45.

Brown, A. L., and K. C. Lam (1987), Levels of ambient noise in Hong Kong, Applied Acoustics, 20, 85-100.

Brune, J. N., and J. Oliver (1959), The seismic noise of the Earth's surface, Bulletin of the Seismological Society of America, 49, 349-353.

Can, A., L. Leclercq, J. Lelong, and D. Botteldooren (2010), Traffic noise spectrum analysis: Dynamic modeling vs. experimental observations, Applied Acoustics, 71(8), 764-770.

Carter, J. A., N. Barstow, P. W. Pomeroy, E. P. Chael, and P. J. Leahy (1991), High-frequency seismic noise as a function of depth, Bulletin of the Seismological Society of America, 81, 1101-1114.

Cionco, R. M., and R. Ellefsen (1998), High resolution urban morphology data for urban wind flow modeling, Atmospheric Environment, 32(1), 7-17.

Ellefsen, R. A. (1987), Urban terrain zone characteristicsRep., DTIC Document.

Frantti, G. E. (1963), The nature of high-frequency earth noise spectra, Geophysics, 28, 547-562.

Given, H. K. (1990), Variations in broadband seismic noise at IRIS/IDA stations in the USSR with implications for event detection, Bulletin of the Seismological Society of America, 80, 2072-2088.

Groos, J. C., and J. R. R. Ritter (2009), Time domain classification and quantification of seismic noise in an urban environment, Geophysical Journal International, 179(2), 1213-1231, doi:10.1111/j.1365-246X.2009.04343.x.

Gutenberg, B. (1931), Microseisms in North America, Bulletin of the Seismological Society of America, 21, 1-24.

Kang, J. (2006), Urban sound environment, 278 pp., Taylor \& Francis.

Li, T. M. C., J. F. Ferguson, E. Herrin, and H. B. Durham (1984), High-frequency seismic noise at Lajitas, Texas, Bulletin of the Seismological Society of America, 74, 2015-2033.

Lynch, E., D. Joyce, and K. Fristrup (2011), An assessment of noise audibility and sound levels in US National Parks, Landscape ecology, 26(9), 1297-1309.

McNamara, D. E., and R. P. Buland (2004), Ambient noise levels in the continental United States, Bulletin of the Seismological Society of America, 94, 1517-1527.

Mennitt, D., K. Sherrill, and K. Fristrup (2014), A geospatial model of ambient sound pressure levels in the contiguous United States, J Acoust Soc Am, 135(5), 2746-2764, doi:10.1121/1.4870481.

Montes González, D., J. M. Barrigón Morillas, and G. Rey Gozalo (2015), The influence of microphone location on the results of urban noise measurements, Applied Acoustics, 90, 6473, doi:10.1016/j.apacoust.2014.11.001. 
Moran, M. L., R. J. Greenfield, and D. K. Wilson (2007), Acoustic array tracking performance under moderately complex environmental conditions, Applied Acoustics, 68(10), 1241-1262.

Peterson, J. (1993), Observations and modeling of seismic background noise, USGS Open File Report 93-222 Rep., US Geological Survey, Albuquerque, NM.

Rehan, R. M. (2015), The phonic identity of the city urban soundscape for sustainable spaces, HBRC Journal.

Riahi, N., and P. Gerstoft (2015), The seismic traffic footprint: Tracking trains, aircraft, and cars seismically, Geophysical Research Letters, 42(8), 2674-2681, doi:10.1002/2015g1063558.

Sheriff, R. E., and L. P. Geldart (1995), Exploration seismology, Cambridge university press.

Steele, C. (2001), A critical review of some traffic noise prediction models, Applied Acoustics, $62,271-287$.

Swanson, D. C. (2011), Signal Processing for Intelligent Sensor Systems with MATLAB®, CRC Press.

To, W. M., R. C. W. Ip, G. C. K. Lam, and C. T. H. Yau (2002), A multiple regression model for urban traffic noise in Hong Kong, Journal of the Acoustical Society of America, 112, 551556.

Wei, W., T. Van Renterghem, B. De Coensel, and D. Botteldooren (2016), Dynamic noise mapping: A map-based interpolation between noise measurements with high temporal resolution, Applied Acoustics, 101, 127-140.

Withers, M. M., R. C. Aster, C. J. Young, and E. P. Chael (1996), High-frequency analysis of seismic background noise as a function of wind speed and shallow depth, Bulletin of the Seismological Society of America, 86, 1507-1515.

Young, C. J., E. P. Chael, M. M. Withers, and R. C. Aster (1996), A comparison of the highfrequency $(>1 \mathrm{~Hz})$ surface and subsurface noise environment at three sites in the United States, Bulletin of the Seismological Society of America, 86, 1516-1528. 


\section{Urban Noise Measurements}
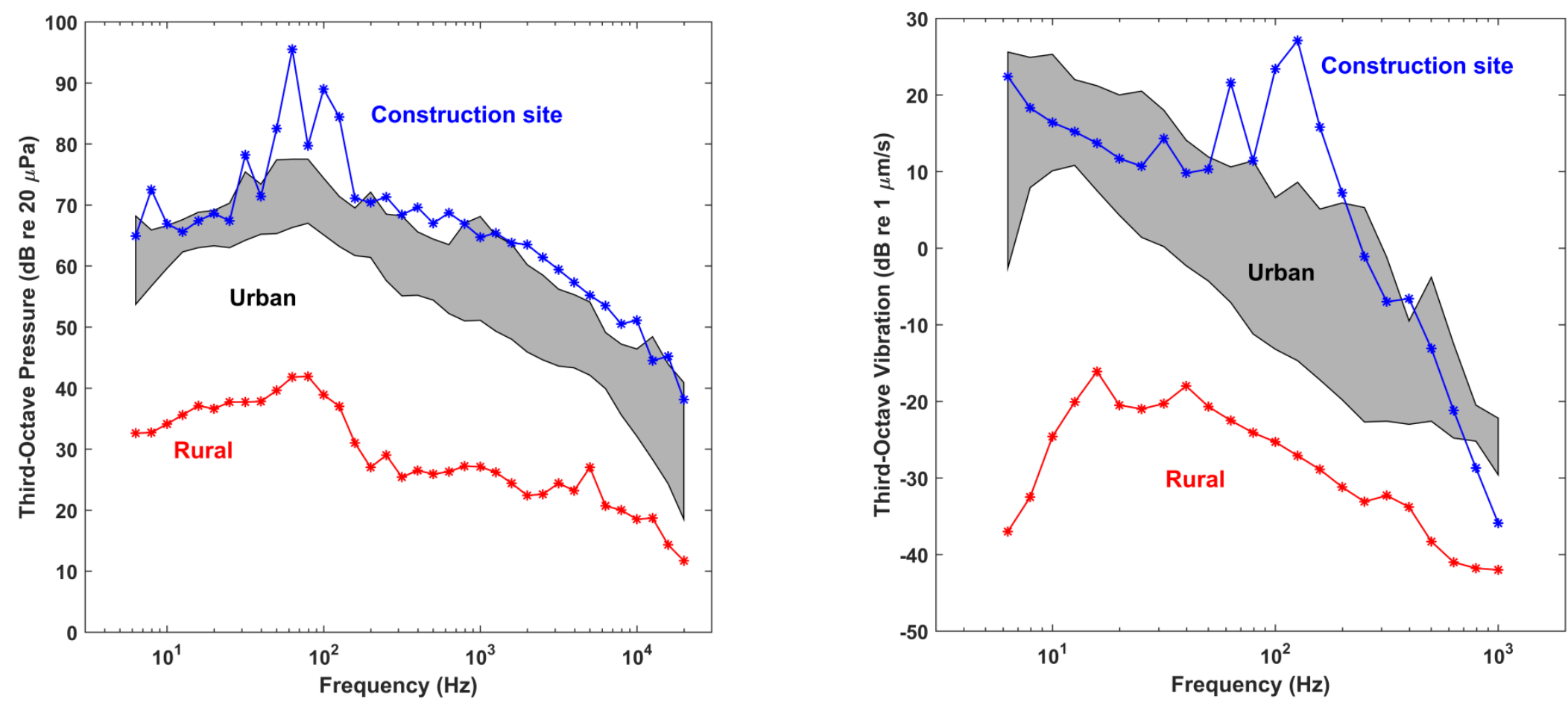